\title{
Phenylpropanoids, lignan glucosides, feruloyltyramines, and flavonoid glycosides, as antioxidative compounds from aerial parts of Suaeda japonica
}

\author{
Gyu-Yeon $\mathrm{Oh}^{1}$, Young-Seung Lee ${ }^{2}$, Tae-Il Jeon ${ }^{2}$, Kyung-Sik Ham³ \\ Jae-Hak Moon ${ }^{1}$, Jeong-Yong $\mathrm{Cho}^{1 *}$ \\ ${ }^{1}$ Department of Food Science and Technology, Chonnam National University, Gwangiu 61186, Korea \\ ${ }^{2}$ Department of Animal Science, Chonnam National University, Gwangju 61186, Korea \\ ${ }^{3}$ Department of Food Biotechnology and Solar Salt Research Center, Mokpo National University, Jeonnam 58554, Korea
}

\begin{abstract}
Sixteen antioxidative compounds were purified and isolated from the aerial parts of Suaeda japonica by column chromatography using Amberlite XAD-2 and octadecylsilane columns and high-performance liquid chromatography. These compounds, esculin (1), citrusin D (2), scopolin (3), cichoriin (4), isorhamnetin 3-O-rutinoside-7-O- $\beta$ D-glucopyranoside (5), 3'-methoxytaxifolin 7- $O$ - $\beta$-D-glucopyranoside $(6),(+)$-lyoniresinol 3a- $O$ - $\beta$-D-glucopyranoside (7), $(2 R, 3 R, 4 S)$-isolariciresinol 3a- $O$ - $\beta$-D-glucopyranoside (8), $N$-cis-feruloyltyramine 4-O- $\beta$-D-glucopyranoside (9), $N$-cis-feruloylmethoxytyramine 4-O- $\beta$-D-glucopyranoside (10), trans-icariside $\mathrm{H}_{1}(11)$, cis-icariside $\mathrm{H}_{1}(12)$, $\mathrm{N}$-transferuloyltyramine 4- $O$ - $\beta$-D-glucopyranoside (13), rutin (14), kaempferol-3- $O$-rutinoside (15), and narcissin (16), were identified for the firtst time in $S$. japonica. The structures of these compounds were determined by mass spectrometry and nuclear magnetic resonance spectroscopic analyses. Among the compounds, 14 showed the highest 1,1-diphenyl2-picrylhydrazyl free radical-scavenging activity and 8 exhibited the highest reactive oxygen species-scavenging activity in Huh7 cells.
\end{abstract}

Key words : Suaeda japonica, antioxidant, lignan glucosides, feruloyltyramines, flavonoid glycosides

\section{Introduction}

Suaeda japonica Makino, belonging to the family Amaranthaceae, is an annual halophyte that grows on tidal flats in Korea, Japan, and Europe (Kim et al., 2002; Wada et al., 2003). The leaves of this plant, which is called "chilmyeoncho" in Korean, change from green to red as the plant grows. Young leaves are typically consumed as seasoned vegetables, salads, or herbs in Korea (Choi et al., 2009). S. japonica has recently been shown to exhibit a strong antioxidative activity (Choi et al., 2009; Kang et al., 2017), prevent insulin resistance (Cho et al., 2014), and inhibit tyrosinase and melanin production in B16BL6 cells (Lee et al., 2011; Lee et al., 2012). Additionally, this plant attenuates neuroinflammation in lipopolysaccharide-treated BV-2 microglial cells (Kang et al., 2013). The strong antioxidative nature of $S$. japonica can be attributed to its chemical constituents, including betacyanins (red pigment), betaine, 2'-hydroxy-6,7-methylenedioxyisoflavone, loliolide, and dehydrovomifoliol (Hayakawa and Agarie, 2010; Kim et al., 2005), and may help inhibit lipid peroxidation and prevent cancer and cardiovascular diseases. However, information regarding the chemical constituents of $S$. japonica is currently limited. In our previous study, we

*Corresponding author. E-mail : jyongcho17@jnu.ac.kr, Phone : +82-62-530-2143, Fax : +82-62-530-2149

Received 18 January 2021; Revised 22 February 2021; Accepted 01 March 2021.

Copyright (c) The Korean Society of Food Preservation.

This is an Open Access article distributed under the terms of the Creative Commons Attribution Non-Commercial License (http://creativecommons.org/licenses/by-nc/4.0) which permits unrestricted non-commercial use, distribution, and reproduction in any medium, provided the original work is properly cited. 
found 18 antioxidative compounds including flavonoids, in the aerial parts of $S$. japonica (Cho et al., 2013b) and identified 16 new antioxidative compounds, including coumarin glucosides, coniferyl alcohol glucosides, lignan glucosides, feruloyltyramine glucosides, and flavonol glycosides. Herein, we describe the isolation and structural determination of 16 antioxidative compounds from the aerial parts of $S$. japonica and evaluated the antioxidative acitivities of the isolated compounds using 1,1-diphenyl-2picrylhydrazyl (DPPH) free radical-scavenging and cellbased reactive oxygen species (ROS) production assays.

\section{Materials and methods}

\section{Materials and chemicals}

The aerial parts of $S$. japonica were collected from Shinan County, Korea in August 2017. The aerial parts were washed with water, dried at $50^{\circ} \mathrm{C}$ for 2 days using a hot air dryer (SY-8000, Samyang, Gimpo, Korea), and then ground to a powder. The powdered aerial parts were preserved at $-20^{\circ} \mathrm{C}$ until fruther use. Hydrogen peroxide $\left(\mathrm{H}_{2} \mathrm{O}_{2}\right), 2^{\prime}, 7^{\prime}-$ dichlorofluorescein diacetate $\left(\mathrm{H}_{2} \mathrm{DCFDA}\right), \mathrm{DPPH}$, quercetin, and ferulic acid were purchased from Sigma-Aldrich Chemical Co. (St. Louis, MO, USA). Human hepatocellular carcinoma Huh7 cells were obtained from the American Type Culture Collection (Manassas, VA, USA). Dulbecco's modified Eagle's medium/high glucose (DMEM) was purchased from GE Healthcare (Logan, UT, USA). Fetal bovine serum (FBS), penicillin/streptomycin (PS), phosphate buffer saline (PBS), and Hank's balanced salt solution (HBSS) were purchased from Thermo Fisher Scientific (Waltham, MA, USA).

\section{Extraction, partition, and isolation}

The powdered aerial parts $(989.1 \mathrm{~g})$ were extracted with hot water $(18 \mathrm{~L})$ at $90^{\circ} \mathrm{C}$ for $15 \mathrm{~min}$ and filtered through a cotton gauze. The residue was re-extracted using hot water $(12 \mathrm{~L})$. The hot water extract solutions were combined and partitioned with $n$-hexane $(3 \times 30 \mathrm{~L})$, chloroform $\left(\mathrm{CHCl}_{3}\right.$; $3 \times 30 \mathrm{~L}$ ), ethyl acetate (EtOAc; $3 \times 30 \mathrm{~L}$ ), and water-saturated $n$-butanol $(\mathrm{BuOH} ; 3 \times 30 \mathrm{~L})$, successively. Each fraction was concentrated at $40^{\circ} \mathrm{C}$ under vacuum using an evaporator (Eyela, N-1100; Eleya, Tokyo, Japan).

The $\mathrm{BuOH}$ fraction $(27.09 \mathrm{~g})$ was loaded onto an
Amberlite XAD-2 column $(396.3 \mathrm{~g}, 4.0 \times 70 \mathrm{~cm}, 587 \mu \mathrm{m}$; Supelco, Bellefonte, PA, USA), and eluted with a step-wise system of water $\left(\mathrm{H}_{2} \mathrm{O}\right) /$ methanol $(\mathrm{MeOH})=10: 0,8: 2,6: 4$, 4:6, 2:8, and 0:10 (v/v, 1,500 $\mathrm{mL}$ each step). Each fraction was spotted on silica gel thin layer chromatography (TLC) plates (silica gel $60 \mathrm{~F}$ 254, $0.25 \mathrm{~mm}$ thickness; Merck, Darmstadt, Germany) and developed with $n$-butanol $/ \mathrm{H}_{2} \mathrm{O} /$ acetic acid $=4: 1: 1(\mathrm{v} / \mathrm{v})$. The free radical-scavenging assay was performed by spraying $200 \mu \mathrm{M}$ DPPH radical ethanol solution onto the TLC plate. Eight fractions (BA to $\mathrm{BH}$ ) with free radical-scavenging activities were grouped based on the silica gel TLC results. Sixteen compounds were purified and isolated from fractions $\mathrm{BC}$ and $\mathrm{BF}$ and their subfractions by medium pressure liquid chromatography (MPLC; Isolera One; Biotage, Uppsala, Sweden) coupled with a SNAP Ultra C18 column (30 g; Biotage, Sweden) and a photodiode array detector, and high performance liquid chromatography (HPLC; Shimadzu, Tokyo, Japan) equipped with a Capcell Pak C18 AQ column $(4.6 \times 250 \mathrm{~mm}$, $5 \mu \mathrm{m}$, Shiseido, Tokyo, Japan; flow rate: $4 \mathrm{~mL} / \mathrm{min}$; UV detection: $254 \mathrm{~nm})$. Fraction $\mathrm{BC}\left(\mathrm{H}_{2} \mathrm{O} / \mathrm{MeOH}=8: 2[\mathrm{v} / \mathrm{v}]\right.$, $1.31 \mathrm{~g}$ ) was separated by octadecylsilane (ODS)-MPLC (linear gradient elution, initial $\mathrm{H}_{2} \mathrm{O}$ /acetonitrile $[\mathrm{MeCN}]=$ 10:0 [v/v] for $6 \mathrm{~min} \rightarrow \mathrm{H}_{2} \mathrm{O} / \mathrm{MeCN}=7: 3[\mathrm{v} / \mathrm{v}]$ for $44 \mathrm{~min}$; flow rate: $25 \mathrm{~mL} / \mathrm{min}$; detection: $220 \mathrm{~nm}$ ) to obtain 12 subfractions (BC1 to BC12). Subfraction BC5 (122.7 mg) was subjected to ODS-MPLC (linear gradient elution, initial $\mathrm{H}_{2} \mathrm{O} / \mathrm{MeCN}=10: 0[\mathrm{v} / \mathrm{v}]$ for $6 \mathrm{~min} \rightarrow \mathrm{H}_{2} \mathrm{O} / \mathrm{MeCN}=7: 3$ [v/v] for $44 \mathrm{~min}$; flow rate: $25 \mathrm{~mL} / \mathrm{min}$; UV detection: 254 $\mathrm{nm}$ ) to yield five subfractions (BC5a to BC5d). Compound $1\left(t_{R}=42.1 \mathrm{~min}, 0.8 \mathrm{mg}\right)$ was separated from subfraction BC5a $(1.7 \mathrm{mg})$ by ODS-HPLC (linear gradient elution, initial $\mathrm{H}_{2} \mathrm{O} / \mathrm{MeOH}=9: 1[\mathrm{v} / \mathrm{v}]$ for $5 \min \rightarrow \mathrm{H}_{2} \mathrm{O} / \mathrm{MeCN}=$ $5: 5[\mathrm{v} / \mathrm{v}]$ for $60 \mathrm{~min})$. Compound $2\left(t_{R}=71.4 \mathrm{~min}, 0.5 \mathrm{mg}\right)$ was purified from subfraction $\mathrm{BC} 5 \mathrm{~b}\left(t_{R}=31.8 \mathrm{~min}, 21.3\right.$ $\mathrm{mg}$ ) by ODS-HPLC (isocratic elution, $25 \%$ aqueous $\mathrm{MeCN}$ ). Fraction BC5c $(19.8 \mathrm{mg})$ was subjected to the ODS-HPLC (isocratic elution, $30 \%$ aqueous $\mathrm{MeOH})$ to yield $\mathbf{3}\left(t_{R}=28.9\right.$ $\mathrm{min}, 1.3 \mathrm{mg})$ and $4\left(t_{R}=31.8 \mathrm{~min}, 1.2 \mathrm{mg}\right)$. Compound 5 $\left(t_{R}=71.8 \mathrm{~min}, 11.9 \mathrm{mg}\right.$ ) was separated from subfraction BC6 (104.9 mg) by ODS-MPLC (linear gradient elution, $\mathrm{H}_{2} \mathrm{O} / \mathrm{MeCN}=10: 0[\mathrm{v} / \mathrm{v}]$ for $6 \mathrm{~min} \rightarrow \mathrm{H}_{2} \mathrm{O} / \mathrm{MeCN}=7: 3[\mathrm{v} / \mathrm{v}]$ for $120 \mathrm{~min})$. Fraction BF (3.57 g) was chromatographed on an ODS column $(300 \mathrm{~g}, 3.0 \times 60 \mathrm{~cm}, 40-63 \mu \mathrm{m}$; Merck, 
Billerica, MA, USA) and eluted with solvent mixtures of $\mathrm{H}_{2} \mathrm{O} / \mathrm{MeCN}=90: 10,85: 15,80: 20,75: 25,70: 30,65: 35$, 60:40 (v/v, $750 \mathrm{~mL}$ each step). Ten subfractions (BF1-BF9, $\mathrm{BF} 11)$ were grouped, and $14\left(\mathrm{BF} 10 ; \mathrm{H}_{2} \mathrm{O} / \mathrm{MeCN}=75: 25\right.$ $[\mathrm{v} / \mathrm{v}], 14.6 \mathrm{mg})$ and $\mathbf{1 6}\left(\mathrm{BF} 12 ; \mathrm{H}_{2} \mathrm{O} / \mathrm{MeCN}=70: 30[\mathrm{v} / \mathrm{v}]\right.$, $1.7 \mathrm{~g})$ were purified and isolated. Compound $6\left(t_{R}=110\right.$ min, $0.9 \mathrm{mg}$ ) from subfraction BF3 (isocratic elution, $\left.\mathrm{H}_{2} \mathrm{O} / \mathrm{MeCN}=88: 12[\mathrm{v} / \mathrm{v}], 24.8 \mathrm{mg}\right), 7\left(t_{R}=162 \mathrm{~min}, 1.8\right.$ $\mathrm{mg}$ ) from subfraction $\mathrm{BF} 4$ (isocratic elution, $\mathrm{H}_{2} \mathrm{O} / \mathrm{MeCN}=$ $88: 12[\mathrm{v} / \mathrm{v}], 75.6 \mathrm{mg}), 8\left(t_{R}=73 \mathrm{~min}, 1.8 \mathrm{mg}\right), 9\left(t_{R}=78\right.$ $\mathrm{min}, 8.1 \mathrm{mg})$, and $10\left(t_{R}=82 \mathrm{~min}, 6.9 \mathrm{mg}\right)$ from subfraction BF5+BC6 (isocratic elution, $\mathrm{H}_{2} \mathrm{O} / \mathrm{MeCN}=85: 15[\mathrm{v} / \mathrm{v}], 45.6$ $\mathrm{mg}), 11\left(t_{R}=133 \mathrm{~min}, 1.8 \mathrm{mg}\right), 12\left(t_{R}=143 \mathrm{~min}, 8.1 \mathrm{mg}\right)$, and $13\left(t_{R}=162 \mathrm{~min}, 6.9 \mathrm{mg}\right)$ from subfraction BF8+BC9 (isocratic elution, $\mathrm{H}_{2} \mathrm{O} / \mathrm{MeCN}=87: 13[\mathrm{v} / \mathrm{v}], 55.6 \mathrm{mg}$ ), and $15\left(t_{R}=60 \mathrm{~min}, 1.7 \mathrm{mg}\right.$ ) from subfraction BF11 (isocratic elution, $\mathrm{H}_{2} \mathrm{O} / \mathrm{MeCN}=87: 13[\mathrm{v} / \mathrm{v}], 146.5 \mathrm{mg}$ ) were purified by ODS-HPLC. The procedure for the purification and isolation of the 16 compounds from the $\mathrm{BuOH}$ layer of $S$. japonica aerial parts is summarized in Fig. 1.

\section{Structural analysis}

The isolated compounds were analyzed by an electrospray ionization mass spectrometry (ESI-MS; Waters, Micromass, Manchester, UK). Nuclear magnetic resonance (NMR) spectra of the isolated compounds were acquired using unity INOVA 500 and 600 spectrometers (Varian, Walnut Creek, CA, USA). The isolated compounds were dissolved in deuterated methanol $\left(\mathrm{CD}_{3} \mathrm{OD} ; \delta_{\mathrm{H}} 3.31, \delta_{\mathrm{C}} 49.15\right.$; Merck Co., Darmstadt, Germany), which is an analytical solvent. Compound 1: ${ }^{1} \mathrm{H}-\mathrm{NMR}\left(600 \mathrm{MHz}, \mathrm{CD}_{3} \mathrm{OD}\right) \delta 6.12(1 \mathrm{H}$, d, $J=9.6 \mathrm{~Hz}, \mathrm{H}-3), 7.75(1 \mathrm{H}, \mathrm{d}, J=9.6 \mathrm{~Hz}, \mathrm{H}-4), 6.72$ (1H, s, H-5), 7.34 (1H, s, H-8), 4.75 (1H, d, J=7.2 Hz, H-1'); ESI-MS (positive) $m / z 341.1[\mathrm{M}+\mathrm{H}]^{+}$.

Compound 2: ${ }^{1} \mathrm{H}-\mathrm{NMR}\left(600 \mathrm{MHz}, \mathrm{CD}_{3} \mathrm{OD}\right) \delta 6.99(1 \mathrm{H}$, d, $J=1.8 \mathrm{~Hz}, \mathrm{H}-2), 7.02(1 \mathrm{H}, \mathrm{d}, J=8.4 \mathrm{~Hz}, \mathrm{H}-5), 6.86$ $(1 \mathrm{H}, \mathrm{dd}, J=8.4,1.8 \mathrm{~Hz}, \mathrm{H}-6), 6.46(1 \mathrm{H}, \mathrm{d}, J=15.9 \mathrm{~Hz}$, H-7), 6.20 (1H, dt, $J=15.9,6.0 \mathrm{~Hz}, \mathrm{H}-8), 4.13(2 \mathrm{H}, \mathrm{dd}$, $J=6.0,1.8 \mathrm{~Hz}, \mathrm{H}-9), 3.79\left(3 \mathrm{H}, \mathrm{s}, 3-\mathrm{OCH}_{3}\right), 4.81(1 \mathrm{H}, \mathrm{d}$, $J=7.8 \mathrm{~Hz}, \mathrm{H}-1$ '); ESI-MS (positive) $m / z 346.1[\mathrm{M}+\mathrm{Na}]^{+}$.

Compound 3: ${ }^{1} \mathrm{H}-\mathrm{NMR}\left(600 \mathrm{MHz}, \mathrm{CD}_{3} \mathrm{OD}\right) \delta 6.14(1 \mathrm{H}$,

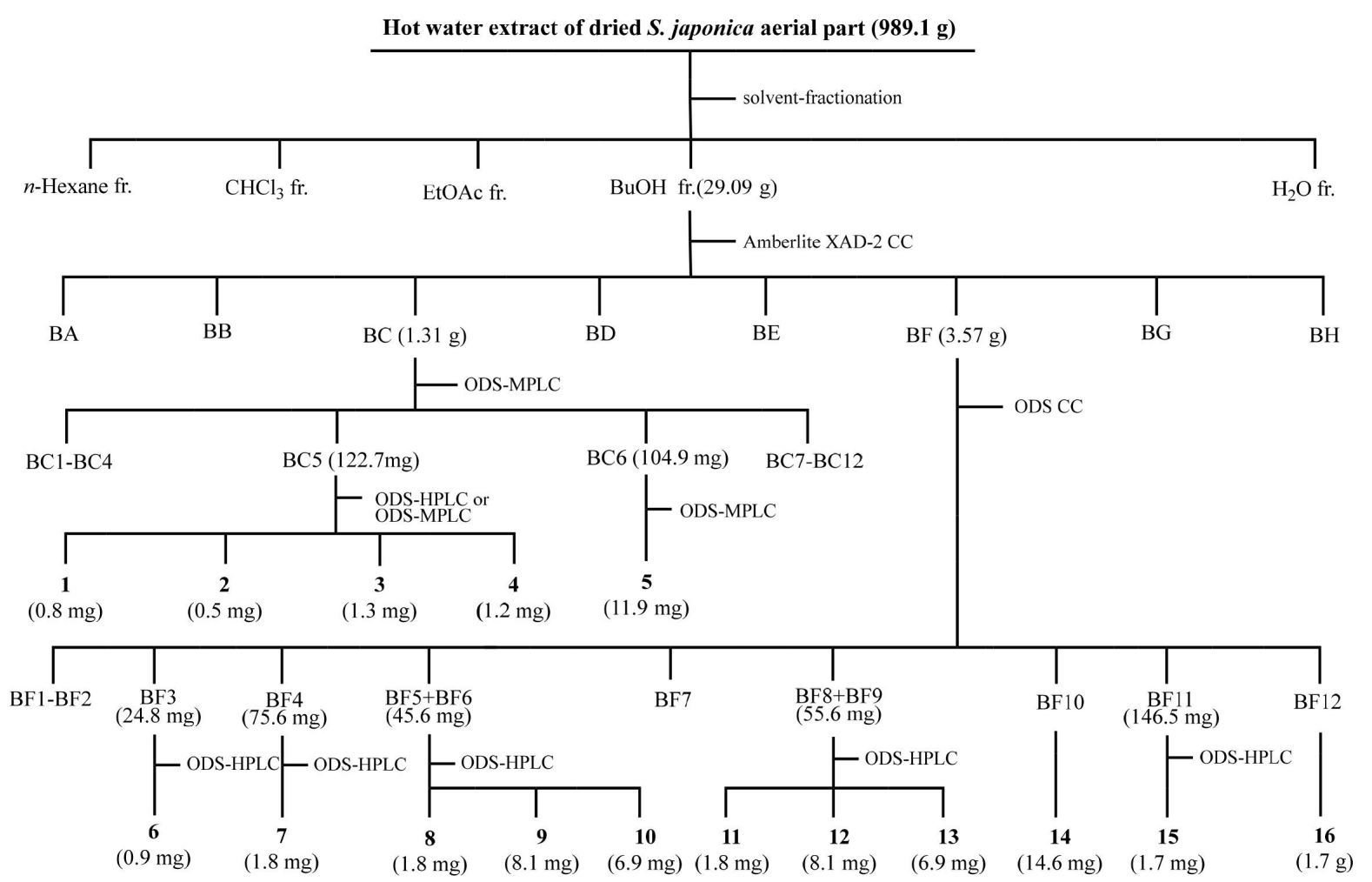

Fig. 1. Procedure for the purification and isolation of $\mathbf{1 6}$ compounds from $\boldsymbol{S}$. japonica aerial part.

Fr., fraction; CC, column chromatography; ODS, octadecylsilane; HPLC, high performance liquid column chromatography; MPLC, medium performance liquid column chromatography. 
d, $J=9.6 \mathrm{~Hz}, \mathrm{H}-3), 7.76(1 \mathrm{H}, \mathrm{d}, J=9.6 \mathrm{~Hz}, \mathrm{H}-4), 7.27$ $(1 \mathrm{H}, \mathrm{s}, \mathrm{H}-5), 6.73(1 \mathrm{H}, \mathrm{s}, \mathrm{H}-8), 3.80\left(3 \mathrm{H}, \mathrm{s},-\mathrm{OCH}_{3}\right), 4.75$ $(1 \mathrm{H}, \mathrm{d}, J=7.8 \mathrm{~Hz}, \mathrm{H}-1$ '); ESI-MS (positive) $\mathrm{m} / \mathrm{z} 355.1$ $[\mathrm{M}+\mathrm{H}]^{+}$.

Compound 4: ${ }^{1} \mathrm{H}-\mathrm{NMR}\left(600 \mathrm{MHz}, \mathrm{CD}_{3} \mathrm{OD}\right) \delta 6.26(1 \mathrm{H}$, d, $J=9.6 \mathrm{~Hz}, \mathrm{H}-3), 7.82(1 \mathrm{H}, \mathrm{d}, J=9.6 \mathrm{~Hz}, \mathrm{H}-4), 7.01$ $(1 \mathrm{H}, \mathrm{s}, \mathrm{H}-5), 7.20(1 \mathrm{H}, \mathrm{s}, \mathrm{H}-8), 4.99(1 \mathrm{H}, \mathrm{d}, J=7.2 \mathrm{~Hz}$, H-1'); ESI-MS (positive) $\mathrm{m} / z 343.1[\mathrm{M}+\mathrm{H}]^{+}$.

Compound 5: ${ }^{1} \mathrm{H}-\mathrm{NMR}\left(600 \mathrm{MHz}, \mathrm{CD}_{3} \mathrm{OD}\right) \delta 6.46(1 \mathrm{H}$, br. d, $J=1.2 \mathrm{~Hz}, \mathrm{H}-6), 6.76(1 \mathrm{H}$, br. s, H-8), $7.91(1 \mathrm{H}, \mathrm{d}$, $\left.J=1.8 \mathrm{~Hz}, \mathrm{H}-2^{\prime}\right), 6.87\left(1 \mathrm{H}, \mathrm{d}, J=8.4 \mathrm{~Hz}, \mathrm{H}-5^{\prime}\right), 7.63(1 \mathrm{H}$, dd, $J=8.4,1.8 \mathrm{~Hz}, \mathrm{H}-6$ '), $3.79\left(3 \mathrm{H}, \mathrm{s}, 3{ }^{\prime}-\mathrm{OCH}_{3}\right), 5.05(1 \mathrm{H}$, d, $J=7.2 \mathrm{~Hz}, \mathrm{H}-1 "), 4.48\left(1 \mathrm{H}, \mathrm{d}, J=1.2 \mathrm{~Hz}, \mathrm{H}-1^{\prime \prime \prime}\right), 1.05$ (3H, d, $\left.J=6.0 \mathrm{~Hz}, \mathrm{H}-6{ }^{\prime \prime \prime}\right), 5.24\left(1 \mathrm{H}, \mathrm{d}, J=7.2 \mathrm{~Hz}, \mathrm{H}-1{ }^{\prime \prime \prime}\right)$; ${ }^{13} \mathrm{C}-\mathrm{NMR}\left(125 \mathrm{MHz}, \mathrm{CD}_{3} \mathrm{OD}\right) \delta 158.18$ (C-2), 135.71 (C-3), 179.65 (C-4), 162.77 (C-5), 101.11 (C-6), 164.70 (C-7), 96.06 (C-8), 159.64 (C-9), 107.63 (C-10), 122.98 (C-1'), 114.67 (C-2'), 151.14 (C-3'), 148.47 (C-4'), 116.22 (C-5'), 123.34 (C-6'), $56.92\left(3^{\prime}-\mathrm{OCH}_{3}\right), 104.07$ (C-1"), 76.12 (C-2"), 78.23 (C-3"), 71.90 (C-4"), 77.53 (C-5"), 68.75 (C-6"), 102.67 (C-1"'), 72.21 (C-2"'), 72.40 (C-3"'), 73.93 (C-4"'), 69.91 (C-5"'), 18.03 (C-6"'), 101.65 (C-1"''), 74.88 (C-2"'"), 77.98 (C-3"'"), 71.45 (C-4"''), 78.57 (C-5"''), 62.63 (C-6"'"); ESI-MS (positive) $m / z 787.3[\mathrm{M}+\mathrm{H}]^{+}$.

Compound 6: ${ }^{1} \mathrm{H}-\mathrm{NMR}\left(600 \mathrm{MHz}, \mathrm{CD}_{3} \mathrm{OD}\right) \delta 4.85(1 \mathrm{H}$, d, $J=12.0 \mathrm{~Hz}, \mathrm{H}-2), 4.30(1 \mathrm{H}, \mathrm{d}, J=12.0 \mathrm{~Hz}, \mathrm{H}-3), 5.99$ $(1 \mathrm{H}, \mathrm{d}, J=2.4 \mathrm{~Hz}, \mathrm{H}-6), 6.35(1 \mathrm{H}, \mathrm{d}, J=2.4 \mathrm{~Hz}, \mathrm{H}-8)$, $6.99\left(1 \mathrm{H}, \mathrm{d}, J=2.4 \mathrm{~Hz}, \mathrm{H}-2^{\prime}\right), 6.74(1 \mathrm{H}, \mathrm{d}, J=8.4 \mathrm{~Hz}$, H-5'), $6.85\left(1 \mathrm{H}, \mathrm{dd}, J=8.4,2.4 \mathrm{~Hz}, \mathrm{H}-6^{\prime}\right), 3.79(3 \mathrm{H}, \mathrm{s}$, 3'- $\left.\mathrm{OCH}_{3}\right), 4.72(1 \mathrm{H}, \mathrm{d}, J=7.8 \mathrm{~Hz}, \mathrm{H}-1 "), 3.35-3.70(4 \mathrm{H}$, m, H-2"-H-5"), 3.66 (1H, dd, $J=12.0,5.4$ Hz, H-6"b), 3.85 $(1 \mathrm{H}, \mathrm{dd}, J=12.0,1.8 \mathrm{~Hz}, \mathrm{H}-6 " \mathrm{a}) ;{ }^{13} \mathrm{C}-\mathrm{NMR}(125 \mathrm{MHz}$, $\left.\mathrm{CD}_{3} \mathrm{OD}\right) \delta 84.68$ (C-2), 74.75 (C-3), 193.64 (C-4), 166.08 (C-5), 99.43 (C-6), 168.24 (C-7), 100.42 (C-8), 162.22 (C-9), 104.37 (C-10), 129.98 (C-1'), 112.52 (C-2'), 149.06 (C-3'), 148.45 (C-4'), 116.11 (C-5'), 122.25 (C-6'), 56.59 (3'-OCH $\left.{ }_{3}\right), 104.37$ (C-1"), 71.34 (C-2"), 78.73 (C-3"), 62.65 (C-4"), 77.52 (C-5"), 62.71 (C-6"); ESI-MS (positive) $\mathrm{m} / \mathrm{z}$ $503.1[\mathrm{M}+\mathrm{Na}]^{+}$.

Compound 7: ${ }^{1} \mathrm{H}-$ and ${ }^{13} \mathrm{C}-\mathrm{NMR}$ data are given in Table 1; ESI-MS (positive) $\mathrm{m} / z$ 605.2 $[\mathrm{M}+\mathrm{Na}]^{+}$.

Compound 8: ${ }^{1} \mathrm{H}$ - and ${ }^{13} \mathrm{C}-\mathrm{NMR}$ data are given in Table 1; ESI-MS (positive) $m / z 545.2[\mathrm{M}+\mathrm{Na}]^{+}$.

Compound 9: ${ }^{1} \mathrm{H}-$ and ${ }^{13} \mathrm{C}-\mathrm{NMR}$ data are given in Table
2; ESI-MS (positive) $\mathrm{m} / z$ 498.2 [M+Na] $]^{+}$.

Compound 10: ${ }^{1} \mathrm{H}$ - and ${ }^{13} \mathrm{C}-\mathrm{NMR}$ data are given in Table 2; ESI-MS (positive) $\mathrm{m} / z 528.2[\mathrm{M}+\mathrm{Na}]^{+}$.

Compound 11: ${ }^{1} \mathrm{H}-\mathrm{NMR}\left(600 \mathrm{MHz}, \mathrm{CD}_{3} \mathrm{OD}\right) \delta 6.76(2 \mathrm{H}$, s, H-2 and H-6), $6.57(1 \mathrm{H}, \mathrm{d}, J=16.2 \mathrm{~Hz}, \mathrm{H}-7), 6.28(1 \mathrm{H}$, $\mathrm{dt}, J=16.2,6.0 \mathrm{~Hz}, \mathrm{H}-8), 4.08(2 \mathrm{H}, \mathrm{dd}, J=6.8,1.8 \mathrm{~Hz}$, $\mathrm{H}-9), 3.86\left(6 \mathrm{H}, \mathrm{s}, 3-\right.$ and $\left.5-\mathrm{OCH}_{3}\right), 3.37\left(3 \mathrm{H}, \mathrm{s}, 4-\mathrm{OCH}_{3}\right)$, $4.89\left(1 \mathrm{H}, \mathrm{d}, J=7.2 \mathrm{~Hz}, \mathrm{H}-\mathrm{l}^{\prime}\right), 3.19-3.79\left(6 \mathrm{H}, \mathrm{m}, \mathrm{H}-2^{\prime}-\right.$ H-6'); ${ }^{13} \mathrm{C}-\mathrm{NMR}\left(125 \mathrm{MHz}, \mathrm{CD}_{3} \mathrm{OD}\right) \delta 135.03$ (C-1), 105.65 (C-2 and C-6), 154.51 (C-3 and C-5), 136.17 (C-4), 133.70 (C-7), 126.90 (C-8), 71.46 (C-9), 105.40 (C-1'), 75.86 (C-2'), 78.51 (C-3'), 74.18 (C-4'), 77.96 (C-5'), 62.70 (C-6'), 57.15 (3- and 5- $\left.\mathrm{OCH}_{3}\right), 58.31\left(4-\mathrm{OCH}_{3}\right)$; ESI-MS (positive) $\mathrm{m} / \mathrm{z} 409.1[\mathrm{M}+\mathrm{Na}]^{+}$.

Compound 12: ${ }^{1} \mathrm{H}-\mathrm{NMR}\left(600 \mathrm{MHz}, \mathrm{CD}_{3} \mathrm{OD}\right) \delta 6.61(2 \mathrm{H}$, s, H-2 and H-6), $6.60(1 \mathrm{H}, \mathrm{d}, J=14.4 \mathrm{~Hz}, \mathrm{H}-7), 5.81(1 \mathrm{H}$, dt, $J=14.4,7.8 \mathrm{~Hz}, \mathrm{H}-8), 4.19(2 \mathrm{H}, \mathrm{dd}, J=7.8,1.8 \mathrm{~Hz}$, $\mathrm{H}-9), 3.86\left(6 \mathrm{H}, \mathrm{s}, 3-\right.$ and $\left.5-\mathrm{OCH}_{3}\right), 3.38\left(3 \mathrm{H}, \mathrm{s}, 4-\mathrm{OCH}_{3}\right)$, $4.92\left(1 \mathrm{H}, \mathrm{d}, J=7.8 \mathrm{~Hz}, \mathrm{H}-1^{\prime}\right), 3.17-3.85\left(6 \mathrm{H}, \mathrm{m}, \mathrm{H}-2^{\prime}-\right.$ H-6'); ESI-MS (positive) $\mathrm{m} / z$ 409.2 $[\mathrm{M}+\mathrm{Na}]^{+}$.

Compound 13: ${ }^{1} \mathrm{H}$ - and ${ }^{13} \mathrm{C}-\mathrm{NMR}$ data are given in Table 2; ESI-MS (positive) $\mathrm{m} / \mathrm{z} 476.2[\mathrm{M}+\mathrm{H}]^{+}$.

Compound 14: ${ }^{1} \mathrm{H}-\mathrm{NMR}\left(500 \mathrm{MHz}, \mathrm{CD}_{3} \mathrm{OD}\right) \delta 6.14(1 \mathrm{H}$, $\mathrm{d}, J=2.5 \mathrm{~Hz}, \mathrm{H}-6), 6.33(1 \mathrm{H}, \mathrm{d}, J=2.0 \mathrm{~Hz}, \mathrm{H}-8), 7.59$ $\left(1 \mathrm{H}, \mathrm{d}, J=2.0 \mathrm{~Hz}, \mathrm{H}-2^{\prime}\right), 6.80\left(1 \mathrm{H}, \mathrm{d}, J=8.5 \mathrm{~Hz}, \mathrm{H}-5^{\prime}\right)$, $7.56\left(1 \mathrm{H}, \mathrm{dd}, J=8.5,2.0 \mathrm{~Hz}, \mathrm{H}-6^{\prime}\right), 5.04(1 \mathrm{H}, \mathrm{d}, J=8.0$ Hz, H-1"), 4.44 (1H, d, $\left.J=1.5 \mathrm{~Hz}, \mathrm{H}-1{ }^{\prime \prime}\right), 3.25-3.82(10 \mathrm{H}$, m, H-2"-H-6" and H-2"'-H-5"'), $1.05(3 \mathrm{H}, \mathrm{d}, J=6.0 \mathrm{~Hz}$, H-6"'); ESI-MS (positive) $m / z 611.2[\mathrm{M}+\mathrm{H}]^{+}$.

Compound 15: ${ }^{1} \mathrm{H}-\mathrm{NMR}\left(500 \mathrm{MHz}, \mathrm{CD}_{3} \mathrm{OD}\right) \delta 6.19(1 \mathrm{H}$, $\mathrm{d}, J=2.0 \mathrm{~Hz}, \mathrm{H}-6), 6.38(1 \mathrm{H}, \mathrm{d}, J=2.0 \mathrm{~Hz}, \mathrm{H}-8), 8.08$ $\left(2 \mathrm{H}, \mathrm{d}, J=8.5 \mathrm{~Hz}, \mathrm{H}-2^{\prime}\right.$ and $\left.\mathrm{H}-6^{\prime}\right), 6.90(2 \mathrm{H}, \mathrm{d}, J=9.0$ $\mathrm{Hz}, \mathrm{H}-3^{\prime}$ and $\left.\mathrm{H}-5^{\prime}\right), 5.11\left(1 \mathrm{H}, \mathrm{d}, J=7.0 \mathrm{~Hz}, \mathrm{H}-1^{\prime \prime}\right), 3.25-$ $3.82\left(10 \mathrm{H}, \mathrm{m}, \mathrm{H}-2^{\prime \prime}-\mathrm{H}-6 "\right.$ and H-2"'-H-5"'), $4.53(1 \mathrm{H}, \mathrm{d}, J$ $\left.=1.5 \mathrm{~Hz}, \mathrm{H}-1{ }^{\prime \prime \prime}\right), 1.14$ (3H, d, $\left.J=6.5 \mathrm{~Hz}, \mathrm{H}-6{ }^{\prime \prime \prime}\right)$; ESI-MS (positive) $\mathrm{m} / \mathrm{z} 595.2[\mathrm{M}+\mathrm{H}]^{+}$.

Compound 16: ${ }^{1} \mathrm{H}-\mathrm{NMR}\left(500 \mathrm{MHz}, \mathrm{CD}_{3} \mathrm{OD}\right) \delta 6.13(1 \mathrm{H}$, $\mathrm{d}, J=2.0 \mathrm{~Hz}, \mathrm{H}-6), 6.33(1 \mathrm{H}, \mathrm{d}, J=2.0 \mathrm{~Hz}, \mathrm{H}-8), 7.86$ $\left(1 \mathrm{H}, \mathrm{d}, J=2.0 \mathrm{~Hz}, \mathrm{H}-2^{\prime}\right), 6.83\left(1 \mathrm{H}, \mathrm{d}, J=8.5 \mathrm{~Hz}, \mathrm{H}-5^{\prime}\right)$, $7.54\left(1 \mathrm{H}, \mathrm{dd}, J=8.5,2.0 \mathrm{~Hz}, \mathrm{H}-6\right.$ '), $3.87\left(3 \mathrm{H}, \mathrm{s}, 3^{\prime}-\mathrm{OCH}_{3}\right)$, $5.15(1 \mathrm{H}, \mathrm{d}, J=7.5 \mathrm{~Hz}, \mathrm{H}-1 "), 3.25-3.83\left(10 \mathrm{H}, \mathrm{m}, \mathrm{H}-2^{\prime \prime}-\right.$ H-6" and H-2"'-H-5"'), 4.44 (1H, d, $\left.J=1.5 \mathrm{~Hz}, \mathrm{H}-1{ }^{\prime \prime}\right), 1.01$ $\left(3 \mathrm{H}, \mathrm{d}, J=6.5 \mathrm{~Hz}, \mathrm{H}-6{ }^{\prime \prime \prime}\right) ;{ }^{13} \mathrm{C}-\mathrm{NMR}\left(125 \mathrm{MHz}, \mathrm{CD}_{3} \mathrm{OD}\right)$

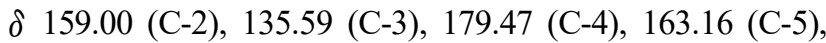


Table 1. ${ }^{1} \mathrm{H}$ - and ${ }^{13} \mathrm{C}$-NMR data of 7 and 8 in $\mathrm{CD}_{3} \mathrm{OD}$

\begin{tabular}{|c|c|c|c|c|}
\hline \multirow{2}{*}{ Position } & \multicolumn{2}{|l|}{7} & \multicolumn{2}{|l|}{8} \\
\hline & $\delta_{\mathrm{H}}($ Int., Multi., $J$ in $\mathrm{Hz})$ & $\delta_{\mathrm{C}}$ & $\delta_{\mathrm{H}}($ Int., Multi., $J$ in $\mathrm{Hz})$ & $\delta_{\mathrm{C}}$ \\
\hline 1 & $2.68(2 \mathrm{H}, \mathrm{m})$ & 34.14 & $2.82(2 \mathrm{H}, \mathrm{dd}, 15.0,10.0)$ & 34.06 \\
\hline 2 & $2.12(1 \mathrm{H}, \mathrm{m})$ & 41.51 & $2.07-2.12(1 \mathrm{H}, \mathrm{m})$ & 39.61 \\
\hline $2 \mathrm{a}$ & $3.71-3.77(2 \mathrm{H}, \mathrm{m})$ & 66.45 & $3.79-3.84(2 \mathrm{H}, \mathrm{m})$ & 65.28 \\
\hline 3 & $1.67-1.70(1 \mathrm{H}, \mathrm{m})$ & 46.88 & $1.83-1.88(1 \mathrm{H}, \mathrm{m})$ & 45.06 \\
\hline $3 a$ & $\begin{array}{c}3.78(1 \mathrm{H}, \mathrm{dd}, 10.0,2.0) \\
3.23(1 \mathrm{H}, \mathrm{m})\end{array}$ & 72.20 & $\begin{array}{l}4.06(1 \mathrm{H}, \mathrm{dd}, 10.0,2.0) \\
3.23(1 \mathrm{H}, \mathrm{dd}, 10.0,3.0)\end{array}$ & 69.52 \\
\hline 4 & $4.21(1 \mathrm{H}, \mathrm{d}, 6.5)$ & 43.55 & $4.08(1 \mathrm{H}, \mathrm{d}, 12.0)$ & 48.03 \\
\hline 5 & - & 148.95 & $6.17(1 \mathrm{H}, \mathrm{s})$ & 117.51 \\
\hline 6 & - & 139.16 & - & 145.95 \\
\hline 7 & - & 147.79 & - & 147.26 \\
\hline 8 & $6.57(1 \mathrm{H}, \mathrm{s})$ & 108.01 & $6.65(1 \mathrm{H}, \mathrm{s})$ & 112.47 \\
\hline 9 & - & 130.46 & - & 129.25 \\
\hline 10 & - & 126.51 & - & 134.52 \\
\hline $1^{\prime}$ & - & 139.75 & - & 138.82 \\
\hline $2^{\prime}$ & $6.41(1 \mathrm{H}, \mathrm{s})$ & 107.28 & $6.79(1 \mathrm{H}, \mathrm{d}, 2.0)$ & 114.42 \\
\hline $3^{\prime}$ & - & 149.25 & - & 149.03 \\
\hline $4^{\prime}$ & - & 134.81 & - & 145.26 \\
\hline $5^{\prime}$ & - & 149.25 & $6.74(1 \mathrm{H}, \mathrm{d}, 8.0)$ & 116.20 \\
\hline $6^{\prime}$ & $6.41(1 \mathrm{H}, \mathrm{s})$ & 107.28 & $6.64(1 \mathrm{H}, \mathrm{dd}, 8.0,2.0)$ & 123.24 \\
\hline $1 "$ & $4.14(1 \mathrm{H}, \mathrm{d}, 6.5)$ & 104.53 & $4.12(1 \mathrm{H}, \mathrm{d}, 7.5)$ & 105.36 \\
\hline $2^{\prime \prime}$ & & 75.34 & & 75.34 \\
\hline $3 "$ & $325370(4 \mathrm{H} \mathrm{m}$ & 78.28 & 322307 (4H $\mathrm{m}$ & 78.03 \\
\hline $4 "$ & $3.35-3 . / 0(4 \mathrm{H}, \mathrm{m})$ & 71.80 & $3.32-3.8 /(4 \mathrm{H}, \mathrm{m})$ & 71.79 \\
\hline $5^{\prime \prime}$ & & 78.45 & & 78.25 \\
\hline $\begin{array}{l}6 " \mathrm{a} \\
6 \mathrm{~b} \mathrm{~b}\end{array}$ & $\begin{array}{l}3.75(1 \mathrm{H}, \mathrm{dd}, 12.0,2.0) \\
3.59(1 \mathrm{H}, \mathrm{dd}, 12.0,5.0)\end{array}$ & 62.95 & $\begin{array}{l}3.83(1 \mathrm{H}, \mathrm{dd}, 12.0,2.0) \\
3.65(1 \mathrm{H}, \mathrm{dd}, 12.0,6.0)\end{array}$ & 62.89 \\
\hline $5-\mathrm{OCH}_{3}$ & $3.86(3 \mathrm{H}, \mathrm{s})$ & 60.35 & - & - \\
\hline $7-\mathrm{OCH}_{3}$ & $3.85(3 \mathrm{H}, \mathrm{s})$ & 56.83 & $3.80(3 \mathrm{H}, \mathrm{s})$ & 56.48 \\
\hline 3'- $-\mathrm{OCH}_{3}$ & $3.75(3 \mathrm{H}, \mathrm{s})$ & 57.14 & $3.81(3 \mathrm{H}, \mathrm{s})$ & 56.58 \\
\hline $5^{\prime}-\mathrm{OCH}_{3}$ & $3.75(3 \mathrm{H}, \mathrm{s})$ & 57.14 & - & - \\
\hline
\end{tabular}

100.13 (C-6), 166.32 (C-7), 95.07 (C-8), 158.69 (C-9), 105.81 (C-10), 123.14 (C-1'), 114.69 (C-2'), 148.46 (C-3'), 150.99 (C-4'), 116.24 (C-5'), 124.12 (C-6'), 56.91 (3'-OCH $\left.{ }_{3}\right)$,
104.54 (C-1"), 76.05 (C-2"), 77.52 (C-3"), 71.77 (C-4"), 78.32 (C-5"), 68.66 (C-6"), 102.66 (C-1"'), 72.22 (C-2"'), 72.41 (C-3"'), 73.97 (C-4"'), 69.93 (C-5"'), 18.03 (C-6"'); 
Table 2. ${ }^{1} \mathrm{H}$ - and ${ }^{13} \mathrm{C}-\mathrm{NMR}$ data of 9,10 , and 13 in $\mathrm{CD}_{3} \mathrm{OD}$

\begin{tabular}{|c|c|c|c|c|c|c|}
\hline \multirow{2}{*}{ Position } & \multicolumn{2}{|l|}{9} & \multicolumn{2}{|l|}{10} & \multicolumn{2}{|l|}{13} \\
\hline & $\delta_{\mathrm{H}}($ Int., Multi., $J$ in $\mathrm{Hz})$ & $\delta_{\mathrm{C}}$ & $\delta_{\mathrm{H}}($ Int., Multi., $J$ in $\mathrm{Hz})$ & $\delta_{\mathrm{C}}$ & $\delta_{\mathrm{H}}($ Int., Multi., $J$ in $\mathrm{Hz})$ & $\delta_{\mathrm{C}}$ \\
\hline 1 & - & 131.25 & - & 129.51 & - & 131.28 \\
\hline 2 & $7.24(1 \mathrm{H}, \mathrm{d}, 2.0)$ & 114.67 & $7.25(1 \mathrm{H}, \mathrm{d}, 2.4)$ & 112.71 & $7.09(1 \mathrm{H}, \mathrm{d}, 1.8)$ & 112.43 \\
\hline 3 & - & 150.26 & - & 147.01 & - & 151.12 \\
\hline 4 & - & 148.43 & - & 146.45 & - & 149.64 \\
\hline 5 & $6.93(1 \mathrm{H}, \mathrm{d}, 8.0)$ & 117.11 & $6.58(1 \mathrm{H} \mathrm{d}, 9.6)$ & 114.32 & $7.07(1 \mathrm{H}, \mathrm{d}, 8.4)$ & 117.68 \\
\hline 6 & $6.85(1 \mathrm{H}, \mathrm{dd}, 8.0,2.0)$ & 124.35 & $6.86(1 \mathrm{H}, \mathrm{dd}, 9.6,2.4)$ & 122.37 & $7.02(1 \mathrm{H}, \mathrm{dd}, 8.4,1.8)$ & 122.84 \\
\hline 7 & $6.53(1 \mathrm{H}, \mathrm{d}, 12.5)$ & 137.71 & $6.53(1 \mathrm{H}, \mathrm{d}, 14.4)$ & 135.70 & $7.36(1 \mathrm{H}, \mathrm{d}, 15.6)$ & 141.48 \\
\hline 8 & $5.79(1 \mathrm{H}, \mathrm{d}, 12.5)$ & 123.41 & $5.80(1 \mathrm{H}, \mathrm{d}, 14.4)$ & 121.33 & $6.39(1 \mathrm{H}, \mathrm{d}, 15.6)$ & 120.61 \\
\hline 9 & - & 170.14 & - & 168.16 & - & 168.94 \\
\hline $3-\mathrm{OCH}_{3}$ & $3.71(3 \mathrm{H}, \mathrm{s})$ & 56.78 & $3.71(3 \mathrm{H}, \mathrm{s})$ & 57.44 & $3.80(3 \mathrm{H}, \mathrm{s})$ & 56.83 \\
\hline $1^{\prime}$ & - & 131.55 & - & 130.03 & - & 131.39 \\
\hline $2^{\prime}$ & $6.57(1 \mathrm{H}, \mathrm{d}, 8.5)$ & 116.37 & $6.66(1 \mathrm{H}, \mathrm{d}, 1.8)$ & 116.49 & $6.62(1 \mathrm{H}, \mathrm{d}, 8.7)$ & 116.40 \\
\hline $3^{\prime}$ & $6.87(1 \mathrm{H}, \mathrm{d}, 8.5)$ & 130.84 & - & 144.12 & $6.96(1 \mathrm{H}, \mathrm{d}, 8.7)$ & 130.88 \\
\hline $4^{\prime}$ & - & 157.03 & - & 148.25 & - & 157.11 \\
\hline $5^{\prime}$ & $6.87(1 \mathrm{H}, \mathrm{d}, 8.5)$ & 130.84 & $6.96(1 \mathrm{H}, \mathrm{d}, 9.6)$ & 115.08 & $6.96(1 \mathrm{H}, \mathrm{d}, 8.7)$ & 130.88 \\
\hline $6^{\prime}$ & $6.57(1 \mathrm{H}, \mathrm{d}, 8.5)$ & 116.37 & $6.49(1 \mathrm{H}, \mathrm{dd}, 9.6,1.8)$ & 120.34 & $6.62(1 \mathrm{H}, \mathrm{d}, 8.7)$ & 116.40 \\
\hline $7^{\prime}$ & $2.57(2 \mathrm{H}, \mathrm{t}, 7.0)$ & 35.65 & $2.59(2 \mathrm{H}, \mathrm{t}, 9.0)$ & 34.10 & $2.66(2 \mathrm{H}, \mathrm{t}, 7.8)$ & 35.92 \\
\hline $8^{\prime}$ & $3.40(2 \mathrm{H}, \mathrm{t}, 7.0)$ & 42.44 & $3.38(2 \mathrm{H}, \mathrm{t}, 9.0)$ & 40.41 & $3.37(2 \mathrm{H}, \mathrm{t}, 7.8)$ & 42.71 \\
\hline 3'- $-\mathrm{OCH}_{3}$ & - & - & $3.67(3 \mathrm{H}, \mathrm{s})$ & 54.45 & - & - \\
\hline $1 "$ & $4.82(1 \mathrm{H}, \mathrm{d}, 7.5)$ & 102.45 & $4.83(1 \mathrm{H}, \mathrm{d}, 8.4)$ & 100.42 & $4.95(1 \mathrm{H}, \mathrm{d}, 7.8)$ & 102.44 \\
\hline $2^{\prime \prime}$ & & 74.95 & & 72.96 & & 74.97 \\
\hline $3 "$ & & 77.92 & & 75.93 & & 78.01 \\
\hline 4" & $3.26-3.75(6 \mathrm{H}, \mathrm{m})$ & 71.38 & $3.25-3.75(6 \mathrm{H}, \mathrm{m})$ & 69.40 & $3.30-3.78(6 \mathrm{H}, \mathrm{m})$ & 71.43 \\
\hline $5^{\prime \prime}$ & & 78.31 & & 76.30 & & 78.43 \\
\hline $6^{\prime \prime}$ & & 62.56 & & 60.59 & & 62.61 \\
\hline
\end{tabular}

ESI-MS (positive) $m / z 625.2[\mathrm{M}+\mathrm{H}]^{+}$.

\section{Determination of DPPH radical-scavenging activity}

The free radical-scavenging activities of 1-16 and ferulic acid (positive control) were evaluated using the DPPH radical (Ban et al., 2018). Solutions of the isolated compounds were prepared at a concentration of $500 \mu \mathrm{M}$ in dimethyl sulfoxide. The DPPH radical ethanol solution $(900 \mu \mathrm{L}$, final concentration of $100 \mu \mathrm{M}$ ) was added to the sample solution
$(100 \mu \mathrm{L})$. Each mixture was kept in the dark for $20 \mathrm{~min}$, and the absorbance was measured at $517 \mathrm{~nm}$. The DPPH radical-scavenging activities of the isolated compounds were calculated as the percentage decrease in the absorbance of the sample solution relative to that of the control.

\section{Determination of cellular antioxidative activity}

Huh7 cells were cultured in a growth medium (DMEM supplemented with $10 \% \mathrm{FBS}$ and $1 \% \mathrm{PS}$ ) at $37^{\circ} \mathrm{C}$ in $5 \%$ 
$\mathrm{CO}_{2}$ incubator. Cells seeded in a 96-well microplate $(7 \times$ $10^{3} /$ well) were treated with the solvent-fractionated fractions $(0.05$ and $0.1 \mathrm{mg} / \mathrm{mL})$, isolated compounds $(20 \mu \mathrm{M})$, and quercetin $(10 \mu \mathrm{M}$, positive control). After incubation for 24

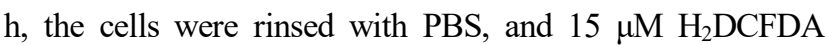
in HBSS was added to the culture. After $30 \mathrm{~min}$, the cells were rinsed with PBS and further incubated with $1 \mathrm{mM}$ $\mathrm{H}_{2} \mathrm{O}_{2}$ in $\mathrm{HBSS}$ at $37^{\circ} \mathrm{C}$ for $30 \mathrm{~min}$. ROS levels were measured using a fluorescence microplate reader (Biotek, Winooski, VT, USA) with excitation and emission wavelengths of $485 \mathrm{~nm}$ and $520 \mathrm{~nm}$, respectively.

\section{Statistical analysis}

Statistical analyses of the antioxidative activities of the solvent-fractionated fractions and the isolated compounds were performed using the Statistical Package for Social Sciences 20.0 package program (SPSS, Chicago, IL, USA). Statistical values were calculated using one-way analysis of variance, followed by Duncan's multiple-range test, and presented as mean \pm standard deviation. Results were considered statistically significant if the p-value was less than 0.05 .

\section{Results and discussion}

\section{Antioxidative activities of solvent-fractionated fractions}

The hot water extracts of the aerial parts of $S$. japonica were solvent-fractionated, yielding $n$-hexane $(0.52 \mathrm{~g}), \mathrm{CHCl}_{3}$ $(0.4 \mathrm{~g})$, EtOAc $(1.55 \mathrm{~g})$, and $\mathrm{BuOH}(27.09 \mathrm{~g})$ fractions. Solvent-fractionated fractions of the aerial parts of $S$. japonica have been previously reported to have antioxidative activities using the DPPH radical, hydroxyl radical, hydrogen radical, hydrogen peroxide, and xanthine oxidase assays (Cho et al., 2013a; Choi et al., 2009; Kang et al., 2017). In this study, the inhibitory activities of the solventfractionated fractions against intracellular ROS generation in Huh7 cells were evaluated by using the $\mathrm{H}_{2}$ DCFDA assay. As shown in Fig. 2, all fractions significantly decreased $\mathrm{H}_{2} \mathrm{O}_{2}$-induced ROS production in Huh7 cells. In particular, the EtOAc fraction (E1) at a concentration of $0.05 \mathrm{mg} / \mathrm{mL}$ exhibited the highest inhibitory activity against $\mathrm{H}_{2} \mathrm{O}_{2}$ induced ROS production in Huh7 cells. The ROS inhibitory activity of the EtOAc fraction (E2) at a concentration of 0.1 $\mathrm{mg} / \mathrm{mL}$ was similar to those of the $n$-hexane (H2) and $\mathrm{CHCl}_{3}(\mathrm{C} 2)$ fractions. The $\mathrm{BuOH}$ fraction had a relatively

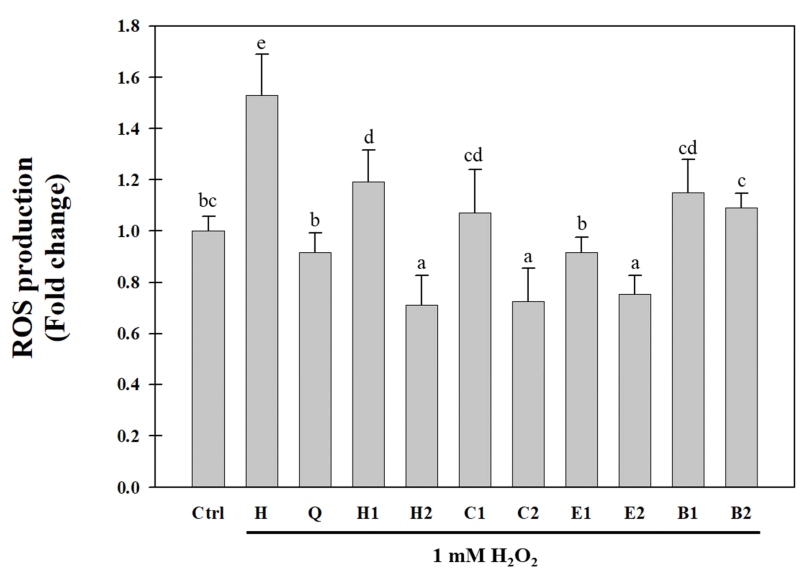

Fig. 2. Cellular antioxidative activities of solvent-fractionated fractions in Huh7 cells.

$\mathbf{H}$, only $\mathrm{H}_{2} \mathrm{O}_{2}$ treatment; $\mathbf{Q}, 20 \mu \mathrm{M}$ quercetin (positive control); H1, 0.05 $\mathrm{mg} / \mathrm{mL} n$-hexane fraction; $\mathbf{H 2}, 0.1 \mathrm{mg} / \mathrm{mL} n$-hexane fraction; $\mathbf{C 1}, 0.05$ $\mathrm{mg} / \mathrm{mL} \mathrm{CHCl}_{3}$ fraction; $\mathbf{C 2}, 0.1 \mathrm{mg} / \mathrm{mL} \mathrm{CHCl}_{3}$ fraction; $\mathbf{E 1}, 0.05 \mathrm{mg} / \mathrm{mL}$ EtOAc fraction; E2, $0.1 \mathrm{mg} / \mathrm{mL}$ EtOAc fraction; B1, $0.05 \mathrm{mg} / \mathrm{mL} \mathrm{BuOH}$ fraction; B2, $0.1 \mathrm{mg} / \mathrm{mL} \mathrm{BuOH}$ fraction. The cells in these fractions and $\mathrm{Q}$ were treated with $1 \mathrm{mM} \mathrm{H} \mathrm{H}_{2} \mathrm{O}_{2}$.

Each value is the mean $\pm \mathrm{SD}$ of three experiments.

${ }^{\mathrm{a}-\mathrm{e}}$ The results with different letters differ significantly $(\mathrm{p}<0.05)$.

low inhibitory activity against ROS generation compared to the other fractions. These results were similar to the radical-scavenging activity results in our previous study (Cho et al., 2013a; Choi et al., 2009). In addition, we identified eight antioxidative compounds, including benzoic acid derivatives, phenylpropanoids, and flavonoids from the $\mathrm{CHCl}_{3}$ and EtOAc fractions obtained after the solvent fractionation of the aerial parts of $S$. japonica. Compared to the $n$-hexane fraction, the $\mathrm{BuOH}$ fraction showed a low inhibitory activity against ROS production and a high DPPH radical-scavenging activity. These results suggested that various antioxidative compounds may be present in the $\mathrm{BuOH}$ fraction. Therefore, we attempted to purify and isolate antioxidative compounds from the $\mathrm{BuOH}$ fraction of the aerial parts of $S$. japonica.

\section{Identification of 16 antioxidative compounds}

Sixteen antioxidative compounds were purified and isolated from the $\mathrm{BuOH}$ fraction of the S. japonica hot water extract. Of these compounds, 11 were identified using MS and NMR data reported previously in the relevant literature. These were esculin (1) (Liu et al., 2005), citrusin D (2) (Li et al., 2011), scopolin (3) (Cho et al., 2016; Zhu et al., 2010), cichoriin (4) (EI-Bassuony and Abdel-Huamid, 
2006), isorhamnetin 3- $O$-rutinoside-7- $O-\beta$-D-glucopyranoside (5) (Aquino et al., 1987), 3'-methoxytaxifolin 7-O- $\beta$-Dglucopyranoside (6) (Cho et al., 2013a), trans-icariside $\mathrm{H}_{1}$ (11) (Hiroyuki et al., 1991), cis-icariside $H_{1}$ (12) (Masahi et al., 2005), rutin (14) (Amen et al., 2014), kaempferol 3-O-rutinoside (15) (Jung et al., 2019), and narcissin (16) (Wu et al., 2017) (Fig. 3). Two lignan glycosides (7 and 8) and three feruloyltyramine glucosides $(\mathbf{9}, \mathbf{1 0}$, and 13) were structurally determined by MS and 1D- and 2D-NMR (heteronuclear single quantum coherence [HSQC], heteronuclear multiple bond correlation $[\mathrm{HMBC}]$, and ${ }^{1} \mathrm{H}-{ }^{1} \mathrm{H}$ correlation spectroscopy [COSY]) experiments.

The molecular weight (522 Da) of $\mathbf{8}$ was established by observing the protonated molecular ion peak at $\mathrm{m} / \mathrm{z} 545.2$ $[\mathrm{M}+\mathrm{Na}]^{+}$in the ESI-MS (positive) spectrum. The ${ }^{1} \mathrm{H}-\mathrm{NMR}$ spectrum (500 $\mathrm{MHz}, \mathrm{CD}_{3} \mathrm{OD}$ ) of $\mathbf{8}$ showed three trisubstituted benzene ring proton signals at $\delta 6.79(1 \mathrm{H}, \mathrm{d}, J$ $\left.=2.0 \mathrm{~Hz}, \mathrm{H}-2^{\prime}\right), 6.74\left(1 \mathrm{H}, \mathrm{d}, J=8.0 \mathrm{~Hz}, \mathrm{H}-5^{\prime}\right)$, and 6.64 $\left(1 \mathrm{H}, \mathrm{dd}, J=8.0,2.0 \mathrm{~Hz}, \mathrm{H}-6^{\prime}\right)$, two para-benzene ring proton signals at $\delta 6.17(1 \mathrm{H}, \mathrm{s}, \mathrm{H}-5)$ and $6.65(1 \mathrm{H}, \mathrm{s}, \mathrm{H}-8)$, and two methoxy proton signals at $\delta 3.80\left(3 \mathrm{H}, \mathrm{s}, 7-\mathrm{OCH}_{3}\right)$ and $3.81\left(3 \mathrm{H}, \mathrm{s}, 3^{\prime}-\mathrm{OCH}_{3}\right)$ (Table 1). Additionally, two methine proton signals at $\delta 2.07-2.12(1 \mathrm{H}, \mathrm{m}, \mathrm{H}-2)$ and 1.83-1.88 $(1 \mathrm{H}, \mathrm{m}, \mathrm{H}-3)$, one methylene proton signal at $\delta$
$2.82(2 \mathrm{H}, \mathrm{dd}, J=15.0,10.0 \mathrm{~Hz}, \mathrm{H}-2)$, and three oxygenated methylene proton signals at $\delta 3.79-3.84(2 \mathrm{H}, \mathrm{m}, \mathrm{H}-2 \mathrm{a})$, $4.06(1 \mathrm{H}, \mathrm{dd}, J=10.0,2.0 \mathrm{~Hz}, \mathrm{H}-3 \mathrm{a})$, and $3.23(1 \mathrm{H}, \mathrm{dd}$, $J=10.0,3.0 \mathrm{~Hz}, \mathrm{H}-3 \mathrm{a}$ ) were observed in the ${ }^{1} \mathrm{H}-\mathrm{NMR}$ spectrum. The presence of the 2,3-dimethylbutan-1,4-diol moiety was confirmed by the correlations of $\mathrm{H}-1 / \mathrm{H}-2$, $\mathrm{H}-2 / \mathrm{H}-2 \mathrm{a}, \mathrm{H}-2 / \mathrm{H}-3, \mathrm{H}-3 / \mathrm{H}-4$, and $\mathrm{H}-3 / \mathrm{H}-3 \mathrm{a}$ in the ${ }^{1} \mathrm{H}-{ }^{1} \mathrm{H}$ COSY spectrum. The aglycone of $\mathbf{8}$ was suggested to be isolariciresinol. The presence of $\beta$-D-glucopyranose was indicated by an anomeric proton signal at $\delta 4.12(1 \mathrm{H}$, d, $J=7.5 \mathrm{~Hz}, \mathrm{H}-1 ")$ and other proton signals at $\delta 3.32-3.87$ observed in the ${ }^{1} \mathrm{H}-\mathrm{NMR}$ spectrum and their coupling constant values $(J=8.0-9.0 \mathrm{~Hz})$, and it was confirmed by their ${ }^{1} \mathrm{H}-{ }^{1} \mathrm{H}$ COSY correlations. The ${ }^{13} \mathrm{C}-\mathrm{NMR}$ spectrum of 8 showed 26 carbon signals, including eight quaternary carbonyl carbons, which were confirmed by the HSQC spectrum. The HMBC spectrum exhibited the correlations of $\delta \quad 6.65(\mathrm{H}-8) / 34.06(\mathrm{C}-1)$ and 145.95 (C-6), $\delta 6.17$ $(\mathrm{H}-5) / 48.03(\mathrm{C}-4)$ and $147.26(\mathrm{C}-7), \delta 3.80\left(7-\mathrm{OCH}_{3}\right) /$ $147.26(\mathrm{C}-7), \delta 6.79\left(\mathrm{H}-2^{\prime}\right)$ and $6.64\left(\mathrm{H}^{-} 6^{\prime}\right) / 149.03\left(\mathrm{C}-3^{\prime}\right)$ and $48.03(\mathrm{C}-4)$, and $\delta 3.81\left(3^{\prime}-\mathrm{OCH}_{3}\right) / 149.03\left(\mathrm{C}-3^{\prime}\right)$, indicating that the aglycone was isolariciresinol. In particular, $\delta 4.12$ (H-1") was correlated to $\delta 69.52$ (C-4) in the HMBC spectrum, indicating that $\mathrm{C}-1$ of glucose was

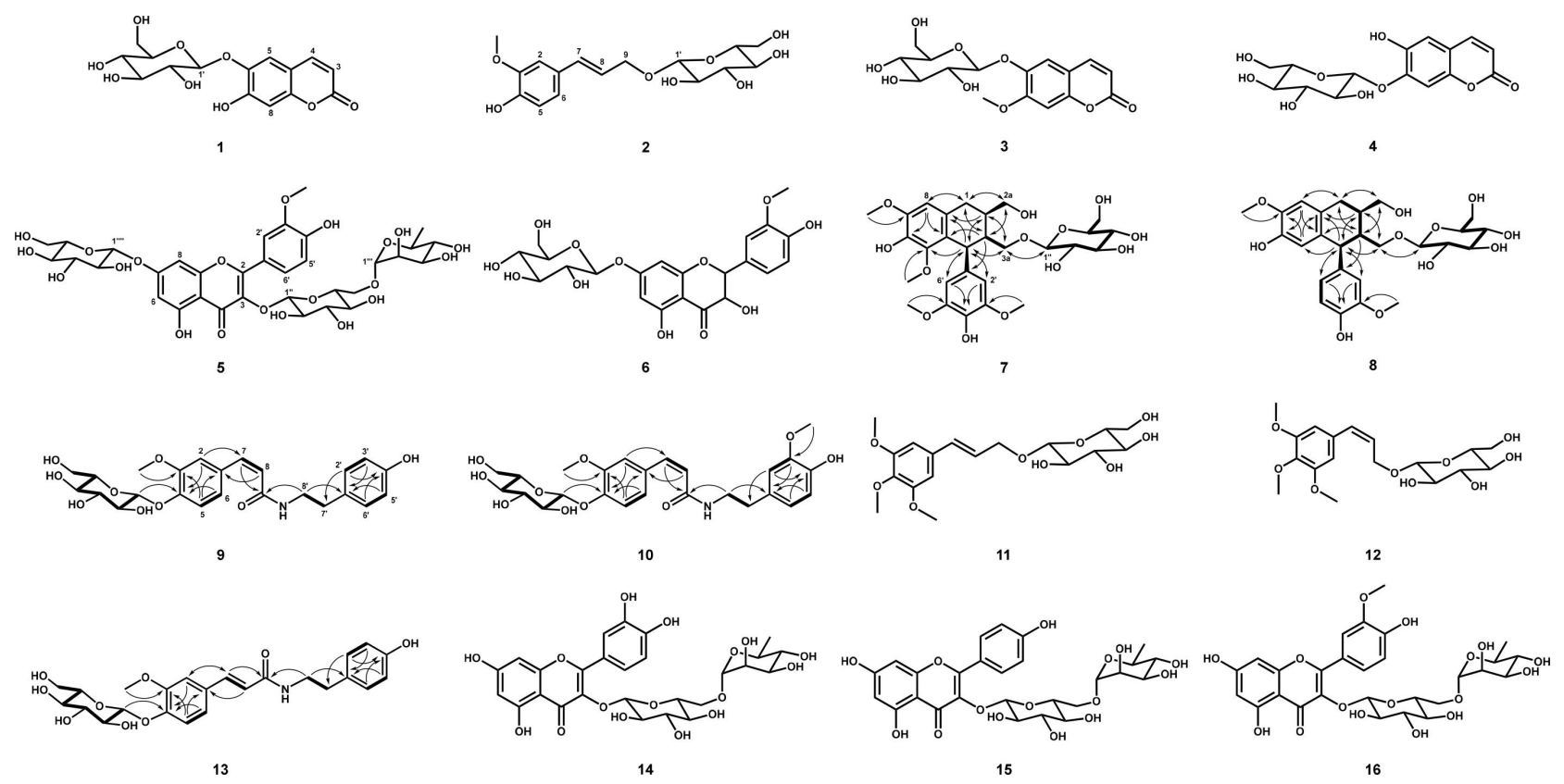

Fig. 3. Structures of the compounds isolated from $S$. japonica and the important ${ }^{1} \mathrm{H}-{ }^{1} \mathrm{H}$ COSY (bold lines) and HMBC (arrows) correlations of 7-10 and 13 . 
etherified to C-3a of the isolariciresinol moiety. The same configuration of $\mathrm{H}-4$ and $\mathrm{H}-2$ was indicated by the enhancement of H-2 at $\delta$ 2.07-2.12 from the irradiation of $\mathrm{H}-4$ at $\delta \quad 4.08$ in the nuclear Overhauser effect (NOE) experiment. Therefore, the structure of $\mathbf{8}$ was determined to be $(2 R, 3 R, 4 S)$-isolariciresinol 3a-O- $\beta$-D-glucopyranoside (Fig. 3).

The molecular weight of 7 (582 Da) was established by observing the sodiated molecular ion peak at $\mathrm{m} / \mathrm{z} 605.2$ $[\mathrm{M}+\mathrm{Na}]^{+}$in the ESI-MS (positive) spectrum. The ${ }^{1} \mathrm{H}-$ and ${ }^{13} \mathrm{C}$-NMR spectra of $\mathbf{7}$ were very similar to those of $\mathbf{8}$. Compared to the ${ }^{1} \mathrm{H}-\mathrm{NMR}$ spectrum of $\mathbf{8}$, the spectrum of 7 showed a $2 \mathrm{H}$ proton signal at $\delta 6.41\left(2 \mathrm{H}, \mathrm{s}, \mathrm{H}-2^{\prime}\right.$ and $\left.\mathrm{H}-6^{\prime}\right)$ and singlet proton signal of the benzene ring at $\delta 6.57$ $(1 \mathrm{H}, \mathrm{s}, \mathrm{H}-8)$ corresponding to the galloyl moiety (Table 1). Additionally, two methoxy proton signals at $\delta 3.86(3 \mathrm{H}, \mathrm{s}$, 5- $\left.\mathrm{OCH}_{3}\right)$ and $3.81\left(6 \mathrm{H}, \mathrm{s}, 3\right.$ '- and 5'- $\left.\mathrm{OCH}_{3}\right)$ were observed. The ${ }^{13} \mathrm{C}$-NMR spectrum of 7 showed 28 carbon signals, including those of three oxygenated quaternary carbonyl carbons at $\delta 147.79$ (C-7) and 149.25 (C-3' and C-5'). The MS and 1D-NMR results suggested that 7 was lyoniresinol glucopyranoside. Consequently, 7 was determined to be $(+)$ lyoniresinol 3a-O- $\beta$-D-glucopyranoside (Fig. 3) by HSQC, ${ }^{1} \mathrm{H}-{ }^{1} \mathrm{H}$ COSY, and HMBC experiments, as well as by comparing the 1D-NMR data of 7 with that of the compound isolated from Stephania hispidula (Yahagi et al., 2010).

The molecular weight (475 Da) of 9 was established by observing the sodiated molecular ion peak at $\mathrm{m} / \mathrm{z} 498.2$ $[\mathrm{M}+\mathrm{Na}]^{+}$in the ESI-MS (positive) spectrum. The ${ }^{1} \mathrm{H}-\mathrm{NMR}$ spectrum ( $500 \mathrm{MHz}, \mathrm{CD}_{3} \mathrm{OD}$ ) of 9 showed the presence of a cis-ferulic acid moiety based on three tri-substituted benzene ring proton signals at $\delta 7.24(1 \mathrm{H}, \mathrm{d}, J=2.0 \mathrm{~Hz}$, $\mathrm{H}-2), 6.93(1 \mathrm{H}, \mathrm{d}, J=8.0 \mathrm{~Hz}, \mathrm{H}-5)$, and $6.85(1 \mathrm{H}, \mathrm{dd}, J$ $=8.0,2.0 \mathrm{~Hz}, \mathrm{H}-6)$, two olefinic double proton signals at $\delta 6.53(1 \mathrm{H}, \mathrm{d}, J=12.5 \mathrm{~Hz}, \mathrm{H}-7)$ and $5.79(1 \mathrm{H}, \mathrm{d}, J=12.5$ $\mathrm{Hz}, \mathrm{H}-8)$, and one methoxy proton signal at $\delta 3.71(3 \mathrm{H}, \mathrm{s}$, $-\mathrm{OCH}_{3}$ ) (Table 2). Additionally, a tyramine moiety corresponding to two $p$-substituted benzene ring proton signals at $\delta 6.57\left(2 \mathrm{H}, \mathrm{d}, J=8.5 \mathrm{~Hz}, \mathrm{H}-2^{\prime}\right.$ and $\left.\mathrm{H}-6^{\prime}\right)$ and $6.87\left(2 \mathrm{H}, \mathrm{d}, J=8.5 \mathrm{~Hz}, \mathrm{H}-3^{\prime}\right.$ and H-5') and two methylene proton signals at $\delta 2.57\left(2 \mathrm{H}, \mathrm{t}, J=7.0 \mathrm{~Hz}, \mathrm{H}-7^{\prime}\right)$ and 3.40 $\left(2 \mathrm{H}, \mathrm{t}, J=7.0 \mathrm{~Hz}, \mathrm{H}-8^{\prime}\right)$ was observed in the ${ }^{1} \mathrm{H}$ NMR spectrum. The ${ }^{13} \mathrm{C}-\mathrm{NMR}$ spectrum of 9 contained 16 carbon signals, including a carbonyl carbon at $\delta 170.14$ (C-9). Based on the MS and 1D-NMR results, the aglycone of 9 was suggested to be feruloyltyramine, which is composed of ferulic acid and tyramine moieties, as identified by ${ }^{1} \mathrm{H}-{ }^{1} \mathrm{H}$ COSY, HSQC, and HMBC experiments. The ${ }^{1} \mathrm{H}-{ }^{1} \mathrm{H}$ COSY correlations of $\mathrm{H}-5 / \mathrm{H}-6, \mathrm{H}-7 / \mathrm{H}-8, \mathrm{H}-2^{\prime}$ and $\mathrm{H}-6^{\prime} / \mathrm{H}-3^{\prime}$ and $\mathrm{H}-5^{\prime}$, and $\mathrm{H}-\mathrm{7}^{\prime} / \mathrm{H}-8^{\prime}$ and the important $\mathrm{HMBC}$ correlations of $\delta 6.53(\mathrm{H}-7)$ to $170.14(\mathrm{C}-9)$ and $114.67(\mathrm{C}-2), \delta 2.57$ $\left(\mathrm{H}-7^{\prime}\right)$ to 116.37 (C-2' and $\left.\mathrm{C}-6^{\prime}\right)$, and $\delta 3.40\left(\mathrm{H}-8^{\prime}\right)$ to 170.14 (C-9) established the connection of feruloyltyramine in 9 (Fig. 3). The presence of one $\beta$-D-glucopyranose was established based on an anomeric proton signal at $\delta 4.82(1 \mathrm{H}, \mathrm{d}, J=$ $7.5 \mathrm{~Hz}, \mathrm{H}-1 ")$ and other proton signals at $\delta 3.26-3.75(6 \mathrm{H}$, H-2"-H-6") in the ${ }^{1} \mathrm{H}-\mathrm{NMR}$ spectrum and six carbon signals at $\delta$ 62.56-102.45 in the ${ }^{13} \mathrm{C}-\mathrm{NMR}$ spectrum, as confirmed by the ${ }^{1} \mathrm{H}-{ }^{1} \mathrm{H}$ COSY correlations. In particular, the HMBC correlation of $\delta 4.82(\mathrm{H}-1 ")$ to 148.43 (C-4) indicated that C-1 of glucose was etherified to C-4 of feruloyltyramine (Fig. 3). Consequently, 9 was determined to be $\mathrm{N}$-cisferuloyltyramine 4-O- $\beta$-D-glucopyranoside (Fig. 3).

The ${ }^{1} \mathrm{H}$ - and ${ }^{13} \mathrm{C}-\mathrm{NMR}$ spectra of $\mathbf{1 0}$ and $\mathbf{1 3}$ were similar to those of $\mathbf{9}$ (Table 2). The feruloyltyramine moieties were identical, while the methoxy group and type of olefinic double bond in these compounds differed. Compounds $\mathbf{1 0}$ and 13 were suggested to be feruloyltyramine glucosides. The molecular weight $(505 \mathrm{Da})$ of $\mathbf{1 0}$ was determined from the protonated molecular ion peak at $m / z 528.2[\mathrm{M}+\mathrm{H}]^{+}$in the ESI-MS (positive) spectrum. The ${ }^{1} \mathrm{H}-\mathrm{NMR}$ spectrum $\left(600 \mathrm{MHz}, \mathrm{CD}_{3} \mathrm{OD}\right)$ of $\mathbf{1 0}$ revealed a tri-substituted benzene ring based on three proton signals at $\delta 6.66(1 \mathrm{H}, \mathrm{d}, J=1.8$ $\left.\mathrm{Hz}, \mathrm{H}-2^{\prime}\right), 6.96\left(1 \mathrm{H}, \mathrm{d}, J=9.6 \mathrm{~Hz}, \mathrm{H}-5^{\prime}\right)$, and $6.49(1 \mathrm{H}$, dd, $\left.J=9.6,1.8 \mathrm{~Hz}, \mathrm{H}-6^{\prime}\right)$ and one methoxy proton signal at $\delta$ $3.67\left(3 \mathrm{H}, \mathrm{s},-\mathrm{OCH}_{3}\right)$ (Table 2), suggesting that the partial structure of $\mathbf{1 0}$ was composed of dopamine (3'-methoxytyramine) instead of tyramine as in $\mathbf{9}$. The ${ }^{13} \mathrm{C}-\mathrm{NMR}$ spectrum of $\mathbf{1 0}$ showed 25 carbon signals, including one carbonyl carbon at $\delta 168.16$ (C-9) and one methoxy carbon at $\delta 54.45$ $\left(-\mathrm{OCH}_{3}\right)$. The molecular weight $(475 \mathrm{Da})$ of $\mathbf{1 3}$ was established by observing the sodiated molecular ion peak at $m / z 476.2[\mathrm{M}+\mathrm{H}]^{+}$in the ESI-MS (positive) spectrum. The trans olefinic double bond proton signals at $\delta 7.36(1 \mathrm{H}, \mathrm{d}$, $J=15.6 \mathrm{~Hz}, \mathrm{H}-7)$ and $6.39(1 \mathrm{H}, \mathrm{d}, J=15.6 \mathrm{~Hz}, \mathrm{H}-8)$ and carbon signals at $\delta 141.48(\mathrm{C}-7)$ and $120.61(\mathrm{C}-8)$ were observed in the ${ }^{1} \mathrm{H}$ - and ${ }^{13} \mathrm{C}-\mathrm{NMR}$ spectra of 13 , and they differed from those of $\mathbf{9}$ (Table 2). Thus, compounds $\mathbf{1 0}$ and 13 were suggested to be $N$-cis-feruloylmethoxytyramine glucopyranoside and $\mathrm{N}$-trans-feruloyltyramine glucopyranoside, respectively. Their accurate structures were established using 
2D-NMR $\left({ }^{1} \mathrm{H}^{-1} \mathrm{H}\right.$ COSY, HSQC, and HMBC) spectra (Fig. $3)$. Therefore, $\mathbf{1 0}$ and $\mathbf{1 3}$ were $N$-cis-feruloylmethoxytyramine 4-O- $\beta$-D-glucopyranoside and $\mathrm{N}$-trans-feruloyltyramine 4-O$\beta$-D-glucopyranoside, respectively (Fig. 3).

\section{DPPH radical-scavenging activity of the isolated compounds}

The free radical-scavenging activities of the isolated compounds (1-16) were evaluated at the same concentration $(50 \mu \mathrm{M})$ using the DPPH radical (final concentration of 100 $\mu \mathrm{M})$. The DPPH radical-scavenging activities of the identified compounds are shown in Fig. 4. Rutin (14) displayed the highest DPPH radical-scavenging activity. It is well known that the catechol structure is an important active site for radical scavenging by phenolic compounds (Burda and Oleszek, 2001). This study confirms that the catechol moiety is an important contributor to the excellent radical-scavenging activity of rutin (14). Compounds 5-10, which have a methoxy-substituted catechol moiety, showed relatively low DPPH radical-scavenging activities compared to rutin. Other compounds showed very low DPPH radical-scavenging activities compared to ferulic acid (positive control).

\section{Inhibitory effect of the isolated compounds on $\mathrm{H}_{2} \mathrm{O}_{2}$-induced intracellular ROS generation in Huh7 cells}

As shown in Fig. 5, the cells treated with the isolated

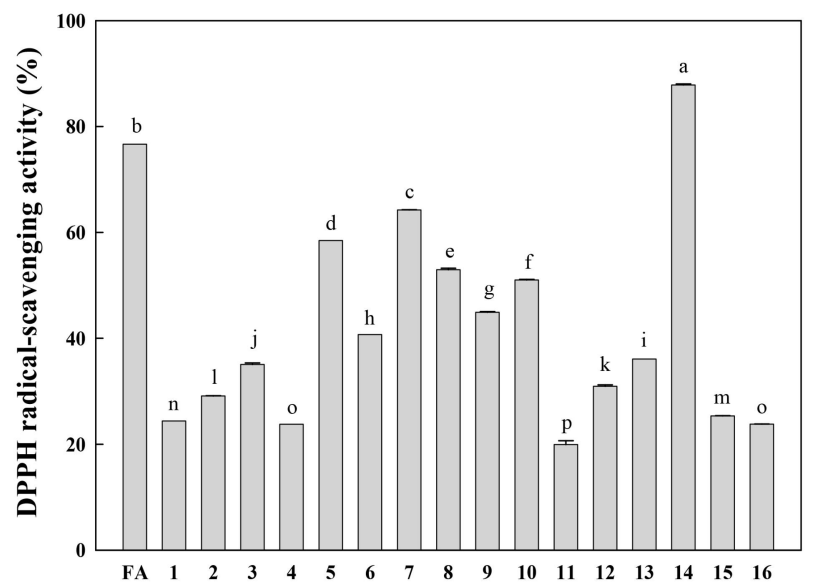

Fig. 4. DPPH radical-scavenging activities of compounds 1-16.

Ferulic acid (FA) was used as a positive control.

Compounds 1-16 and FA were assayed at the concentration of $50 \mu \mathrm{M}$ Each value is the mean $\pm \mathrm{SD}$ of three experiments.

${ }^{\mathrm{a}-\mathrm{p}}$ The results with different letters differ significantly $(\mathrm{p}<0.05)$. compounds (1-16) exhibited significantly reduced intracellular ROS generation compared to $\mathrm{H}_{2} \mathrm{O}_{2}$-treated cells. Interestingly, the isolated compounds (1-16) differed only slightly in terms of their ROS inhibitory activities, which were relatively lower than that of quercetin (positive control). Of the isolated compounds, 2, 6-10, 14, and 16 showed higher antioxidative activities against $\mathrm{H}_{2} \mathrm{O}_{2}$-induced ROS generation than that induced by other compounds, with $\mathbf{8}$ exhibiting a relatively high intracellular ROS-scavenging activity compared to the other compounds. $\mathrm{H}_{2} \mathrm{O}_{2}$ is a toxic, strong free radical generator that induces oxidative stress during cellular metabolism (Phaniendra et al., 2015). Our results indicated that the isolated compounds (1-16) exert cellular antioxidative activities via ROS scavenging to protect cells against oxidative stress.

In this study, 16 antioxidative compounds, including three coumarin glucosides $(\mathbf{1}, \mathbf{3}$, and $\mathbf{4})$, three coniferyl alcohol glucosides $(\mathbf{2}, \mathbf{1 1}$, and 12), two lignin glucosides (7 and 8), three feruloyltyramine glucosides $(\mathbf{9}, \mathbf{1 0}$, and $\mathbf{1 3})$, and five flavonol glycosides (5, 6, and 14-16), were isolated and identified from the aerial parts of $S$. japonica. To the best of our knowledge, these compounds have been identified for the first time in this plant. Among these compounds, narcissin (16) was purified and isolated in the largest amount. Narcissin has been reported to have antioxidative, antimicrobial, and immunomodulatory activities (EI-Aasr et

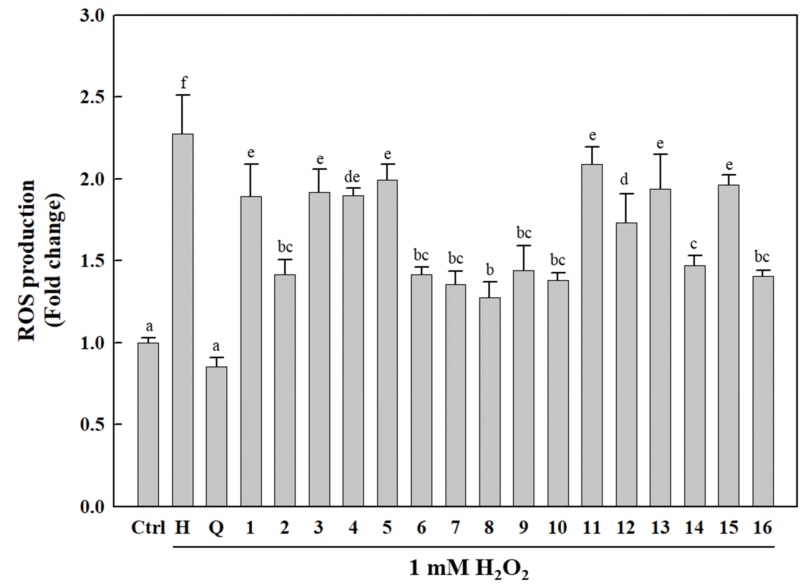

Fig. 5. Cellular antioxidative activities of compounds 1-16 in Huh7 cells.

$\mathrm{H}$ was treated by only $\mathrm{H}_{2} \mathrm{O}_{2}$. Quercetin $(\mathrm{Q}, 20 \mu \mathrm{M})$ was used as a positive control. The concentration of 1-16 in the assay were $20 \mu \mathrm{M}$.

The cells for 1-16 and Q were treated with $1 \mathrm{mM} \mathrm{H}_{2} \mathrm{O}_{2}$.

Each value is the mean \pm SD of three experiments.

${ }^{\mathrm{a}-\mathrm{f}}$ The results with different letters differ significantly $(\mathrm{p}<0.05)$. 
al., 2016; Lee et al., 2003). Therefore, this compound may be used as a marker for quality control during food processing of $S$. japonica. In addition, the 16 antioxidative compounds identified in this study effectively scavenged the DPPH radical and reduced $\mathrm{H}_{2} \mathrm{O}_{2}$-induced ROS production in cells. Phenolic compounds protect cells against oxidative stress via hydrogen donation, free radical scavenging, and excessive ROS reduction (Murphy and Smith, 2007; Shirai et al., 2001; Terao, 2017). In our previous study, 16 phenolic compounds, including quercetin and luteolin, scavenged free radicals and inhibited lipid peroxidation in ferric ioninduced rat liver homogenate (Cho et al., 2013b). Thus, the various antioxidative phenolic compounds found in $S$. japonica can confer protection against oxidative stress and provide useful information for the utilization of $S$. japonica as a food and medicinal herb. Further studies on the mechanism of absorption of these antioxidative compounds in the body and the extent to which $S$. japonica reduces oxidative stress are necessary.

\section{Acknowledgments}

This study was financially supported by Chonnam National University (Grant No. 2019-0233).

\section{Conflict of interests}

The authors declare no potential conflict of interest.

\section{ORCID}

Gyu-Yeon Oh https://orcid.org/0000-0003-0726-8328

Jeong-Yong Cho https://orcid.org/0000-0002-2048-5661

\section{References}

Amen YM, Marzouk AM, Zaghlool MG, Afifi MS. A new acylated flavonoid tetraglycoside with anti-inflammatory activity from Tipuana tipu leaves. Nat Prod Res, 29, 511-517 (2014)

Aquino R, Behar I, Dagostino M, Simone FD, Shettino O,

Pizza C. Phytochemical investigation on Mercurialis annua. Biochem Syst Ecol, 15, 667-669 (1987)

Ban EJ, Kim JH, Oh GY, Lee SY, Moon JH, Cho JY.
Comparison of the antioxidative activities and bioactive compound contents of green tea, roasted green tea, and black tea. J Kor Tea Soc, 24, 64-71 (2018)

Burda S, Oleszek W. Antioxidant and antiradical activities of flavonoids. J Agric Food Chem, 49, 2774-2779 (2001)

Cho JG, Song NY, Nam TG, Shrestha S, Park HJ, Lyu HN, Kim DO, Lee GH, Woo YM, Jeong TS, Baek MI. Flavonoids from the grains of $\mathrm{C} 1 / \mathrm{R}-\mathrm{S}$ transgenic rice, the transgenic Oryza sativa spp. japonica, and their radical scavenging activities. J Agric Food Chem, 61, 10354-10359 (2013a)

Cho JY, Huang Z, Park SY, Park KH, Pai TK, Kim SY, Kim HR, Ham KS. The effects of several halophytes on insulin resistance in Otsuka Long-Evans Tokushima Fatty rats. Korean J Food Sci Tecnhol, 46, 100-107 (2014)

Cho JY, Jeong SJ, Lee HL, Park KH, Hwang DY, Park SY, Lee YG, Moon JH, Ham KS. Sesquiterpene lactones and scopoletins from Artemisia scoparia Waldst. \& Kit. and their angiotensin I-converting enzyme inhibitory activities. Food Sci Biotechnol, 25, 1701-1708 (2016)

Cho JY, Yang X, Park KH, Park HJ, Park SY, Moon JH, Ham KS. Isolation and identification of antioxidative compounds and their activities from Suaeda japonica. Food Sci Biotechnol, 22, 1547-1557 (2013b)

Choi JI, Kim YJ, Kim JH, Song BS, Yoon YH, Byun MW, Kwon JH, Chun SS, Lee JW. Antioxidant activities of the extract fractions from Suaeda japonica. J Korean Soc Food Sci Nutr, 38, 131-135 (2009)

El-Asar M, Kabbash A, EI-Seoud KAA, Al-Madboly LA, Ikeda T. Antimicrobial and immunomodulatory activities of flavonol glycosides isolated from Atriplex halimus L. herb. J Pharm Sci Res, 8, 1159-1168 (2016)

El-Bassuony AA, Abdel-Hamid NM. Antibacterial coumarins isolated from Launaea resedifolia. Chem Plant Raw Mater, 1, 65-68 (2006)

Hayakawa K, Agarie S. Physiological roles of betacyanin in a halophyte, Suaeda japonica Makino. Plant Prod Sci, 13, 351-359 (2010)

Hiroyuki M, Toshio M, Akira U. Lignan and terpene glycosides from Epimedium sagittatum. Phytochemistry, 30, 2025-2027 (1991)

Jung SY, Lee MS, Choi AJ, Kim CT, Kim Y. Antiinflammatory effects of high hydrostatic pressure extract of mulberry (Morus alba) fruit on LPS-stimulated 
RAW264.7 cells. Molecules, 24, 1425 (2019)

Kang H, Koppula S, Kim HK, Park TK. Suaeda japonica Makino attenuates lipopolysaccharide-induced neuroinflammatory response in BV-2 microglia via NF-kappa B signaling. Trop J Pharm Res, 12, 351-356 (2013)

Kang KY, Hwang YH, Lee SJ, Kim JJ, Nam SJ, Yee ST. Verification of the antioxidant activity of a subterranean part of Suaeda japonica Makino. Ind Crops Prod, 109, 836-842 (2017)

Kim JA, Choo YS, Lee IJ, Bae JJ, Kim IS, Choo BH, Song SD. Adaptations and physiological characteristics of three Chenopodiaceae species under saline environments. Korean J Ecol, 25, 171-177 (2002)

Kim JS, Lee SH, Son EM, Pan X, Kim YA, Lee GS, Seo YW, Lee BJ. Phytochemical constituents of Suaeda japonica Makino. J Crop Sci, 50, 208-210 (2005)

Lee EH, Kim HJ, Song YS, Jin CB, Lee KT, Cho JS, Lee YS. Constituents of the stems and fruits of Opuntia ficus-indica var. saboten. Arch Pham Res, 26, 10181023 (2003)

Lee KS, Gim JC, Son SM, Lee KY. Antioxidative effects of Suaeda japonica ethanol extract and solvent partitioned fractions. J Korean Soc Food Sci Nutr, 40, 804-808 (2011)

Lee KS, Kim AJ, Lee KY. Analysis of chemical composition and antioxidant activity of Suaeda japonica. J East Asian Soc Diet Life, 22, 521-526 (2012)

Li XD, Kang ST, Li GY, Li X, Wang JH. Synthesis of some phenylpropanoid glycosides (PPGs) and their acetylcholinesterase/xanthine oxidase inhibitory activities. Molecules, 16, 3580-3596 (2011)

Liu R, Sun Q, Sun A, Cui J. Isolation and purification of coumarin compounds from Cortex fraxinus by highspeed counter-current chromatography. J Chromatogr A, 1072, 195-199 (2005)
Masashi K, Hiroyuki A. Simple preparation of phenylpropenoidD-glucopyranoside congeners by Mizoroki-Heck type reaction using organoboron reagents. Tetrahedron, 61, 10559-10568 (2005)

Murphy MP, Smith RAJ. Targeting antioxidants to mitochondria by conjugation to lipophilic cations. Annu Rev Pharmacol Toxicol, 47, 629-656 (2007)

Phaniendra A, Jestadi DB, Periyasamy L. Free radicals: properties, sources, targets, and their implication in various diseases. Ind J Clin Biochem, 30, 11-26 (2015)

Shirai M, Moon JH, Tsushida T, Terao J. Inhibitory effect of a quercetin metabolite, quercetin 3- $O-\beta$-D-glucuronide, on lipid peroxidation in liposomal membranes. J Agric Food Chem, 49, 5602-5608 (2001)

Terao J. Factors modulating bioavailability of quercetinrelated flavonoids and the consequences of their vascular function. Biochem Pharmacol, 139, 15-23 (2017)

Wada N, Zhang J, Jinno N, Okubo A, Yamazaki S. Component analysis of a halophyte, Suaeda japonica, grown on the shore of Ariake sea. Bunseki Kagaku, 52, 843-846 (2003)

Wu H, Zhang G, Huang L, Pang H, Zhang N, Chen Y, Wang G. Hepatoprotective effect of polyphenol-enriched fraction from Folium microcos on oxidative stress and apoptosis in acetaminophen-induced liver injury in mice. Oxid Med Cell Longevity, 2017, 1-14 (2017)

Yahagi T, Yamashita Y, Daikonnya A, Wu JB, Kitanaka S. New feruloyl tyramine glycosides from Stephania hispidula Yamamoto. Chem Pharm Bull, 58, 415-417 (2010)

Zhu Y, Zhang LX, Zhao Y, Huang GD. Unusual sesquiterpene lactones with a new carbon skeleton and new acetylenes from Ajania prezewalskii. Food Chem, 118, 228-238 (2010) 